\section{Viewpoint: vaccine inequity in the spotlight}

\author{
Mustapha Bittaye, ${ }^{1}$ Effua Usuf, ${ }^{2}$ Ed Clarke (i) ${ }^{3}$
}

Vaccine inequity has never before been in the public eye as it has been in the last months. The profound inequities in COVID-19 vaccine supply which have been allowed to develop, driven largely by perceived national self-interest, reached the world stage at the G7 meeting in June. Despite this, less than $2 \%$ of the population of many lowincome African countries have been vaccinated against COVID-19, while more than half of those living in most high-income settings have received at least one, and in many case two vaccine doses. An increasing number of countries are now vaccinating children from the age of 12 , despite risk-benefit analysis being less certain, and are stock-piling vaccines for booster immunisations, in the absence of indication that these will be required on widespread basis. Both approaches are in direct conflict with the current position of the WHO.

The primary arguments that have been put forward to address these inequities have focused on self-protection ('Nobody is safe until everybody is safe') and on ensuring global economic recovery. An expectation that counties will donate 'surplus' vaccines has also largely replaced the premise of vaccine equity. Although it may be that only arguments appealing ultimately to national self-interest have the necessary traction, they are largely specific to pandemic COVID-19 vaccination, thus do not put the current inequalities in their wider context. Such context is essential, given the ultimate aim must surely be to minimise all excess vaccine-preventable deaths due to the pandemic, rather than solely those deaths directly attributable to SARS-CoV-2 infection.

${ }^{1}$ Ministry of Health, Government of The Gambia, Banjul, Gambia

${ }^{2}$ Disease Control and Elimination Theme, Medical Research Council Unit The Gambia at the London School of Hygiene and Tropical Medicine, Banjul, Gambia

${ }^{3}$ Vaccines and Immunity Theme, Medical Research Council Unit The Gambia at the London School of Hygiene and Tropical Medicine, PO Box 273, Banjul, The Gambia, Banjul, Gambia

Correspondence to Dr Ed Clarke, Vaccines and Immunity, Medical Research Council Unit The Gambia at the London School of Hygiene and Tropical Medicine, Banjul, Gambia; Ed.Clarke@Ishtm.ac.uk
Modelling studies and WHO policy recommendations have supported sustaining routine childhood immunisation throughout the pandemic. ${ }^{1} 2$ However, vaccine programmes in many countries in sub-Saharan Africa are fragile; having limited capacity to cover for either delays in vaccine supply, or for having additional demands placed on staff and resources-both of which have occurred to an unprecedented level during the current pandemic. Mass vaccination campaigns, including for measles and polio, which are essential to maintaining population immunity and to outbreak response, have also been delayed. In addition, reductions in vaccination coverage for such programmatic reasons are being multiplied by misinformation and rumours circulating, for example, suggesting COVID-19 vaccines are being deployed in Africa for the purpose of population control. ${ }^{3}$ From our own experience in The Gambia, such rumours are having a negative impact on vaccine confidence overall and hence on the uptake of other vaccines.

Given these factors, progress addressing the pre-existing inequities in the availability of life-saving vaccines across sub-Saharan African, as set out last year in the Immunization Agenda 2030_itself a roadmap to "leave no one behind"4-will be reversed if not considered in tandem with efforts to address the current inequity in COVID-19 vaccine supply. Hundreds of thousands of under 5 years old continue to die annually from vaccine-preventable pneumococcal and Haemophilus influenzae type b disease, and from rotavirus diarrhoea. The number of preventable deaths from measles increased to beyond 200000 again globally in 2019 and any transient reduction in cases reported during the pandemic due to reduced population movement and social mixing, combined with compromised surveillance, are expected to rebound. Polio eradication is also at a critical juncture as cases of vaccine-derived poliovirus increase rapidly, particularly in West Africa. The 2022-2026 Polio Eradication Strategy, launched in June this year, emphasises the critical need to address polio vaccination, not in isolation, but as part of the wider vaccination programme and may thus be considered as a benchmark for future COVID-19 vaccination. ${ }^{5}$ Existing inequities in the availability of human papillomavirus (HPV) vaccines mean that, without action, women will continue to die from cervical cancer in Africa for decades to come, while high-income settings reach elimination goals. These and other inequities disproportionately impact on the health and well-being of children and women. Therefore, addressing them is also vital if key Sustainable Development Goal targets are to be met.

The current sporadic and unpredictable delivery of short shelf-life COVID-19 vaccines, particularly from different manufacturers, through the COVAX facility and other mechanisms, will continue to make it logistically difficult to attain high coverage, even in frontline healthcare workers and other priority groups. It is also the most sure-fire way of maximising ongoing disruption to other vaccination programmes and of driving public mistrust and reduce vaccine confidence overall. WHO figures indicate that global diphtheria, tetanus and pertussis vaccine coverage in infancy fell by $3 \%$, to $83 \%$ in 2020 . The number of 'zerodose', completely unvaccinated children increased by nearly 3.5 million, while the number of girls who were incompletely vaccinated against HPV rose by 1.6 million. ${ }^{6}$ There is currently a very real danger that a profound and longlasting legacy of the current pandemic will be in the lives of children and women lost now, and in the future, due to other vaccine-preventable diseases.

Achieving nominal, although delayed, equity in COVID-19 vaccine coverage is essential if an ongoing cycle of disruption is to be prevented. Countries that have already achieved high coverage must show leadership in ensuring that doses expected by COVAX are prioritised over their own secondary needs. Manufacturers must deliver on their obligations to the facility, rather than focusing on servicing of bilateral agreements with individual countries. Countries in receipt of COVID-19 vaccines must align strategies that focus on empowering and protecting the most vulnerable members of their population, with approaches that will promote, rather than disrupt, child and adolescent programmes. Finally, professional bodies, as well as individuals, 
with a genuine belief in the importance of equity must look beyond their own shores, and advocate for the importance of this unassailable principal, rather than on increasing inequity through focussing on marginal gains at home.

The unprecedented attention that vaccines and vaccine inequity have received in the past months, including the undoubted achievements as well as challenges, should be viewed as a springboard to ensure the goal of the Immunization Agenda 2030 to leave no one behind is ultimately realised.

Contributors EC wrote the first draft of the manuscript. EF and MB reviewed and provided significant input into the final content.

Funding The authors have not declared a specific grant for this research from any funding agency in the public, commercial or not-for-profit sectors.

Competing interests None declared.

Patient consent for publication Not applicable.
Provenance and peer review Not commissioned; internally peer reviewed.

\section{(2) \\ OPEN ACCESS}

Open access This is an open access article distributed in accordance with the Creative Commons Attribution Non Commercial (CC BY-NC 4.0) license, which permits others to distribute, remix, adapt, build upon this work non-commercially, and license their derivative works on different terms, provided the original work is properly cited, appropriate credit is given, any changes made indicated, and the use is non-commercial. See: http:// creativecommons.org/licenses/by-nc/4.0/.

(c) Author(s) (or their employer(s)) 2021. Re-use permitted under CC BY-NC. No commercial re-use. See rights and permissions. Published by BMJ.

\section{Check for updates}

To cite Bittaye M, Usuf E, Clarke E. Arch Dis Child Epub ahead of print: [please include Day Month Year]. doi:10.1136/archdischild-2021-322940

Received 29 July 2021
Accepted 21 September 2021

Arch Dis Child 2021:0:1-2.

doi:10.1136/archdischild-2021-322940

ORCID iD

Ed Clarke http://orcid.org/0000-0002-7785-0340

\section{REFERENCES}

1 Abbas K, Procter SR, van Zandvoort K, et al. Routine childhood immunisation during the COVID-19 pandemic in Africa: a benefit-risk analysis of health benefits versus excess risk of SARS-CoV-2 infection. Lancet Glob Health 2020;8:e1264-72.

2 WHO. Immunization as an essential health service: guiding principles for immunization activities during the COVID-19 pandemic and other times of severe disruption. Geneva: World Health Organization, 2020.

3 Afolabi AA, llesanmi OS. Dealing with vaccine hesitancy in Africa: the prospective COVID-19 vaccine context. Pan Afr Med J 2021;38:3.

4 WHO. 'Immunization agenda 2030: a global strategy to leave no one behind', 2020.

5 GPEI. Delivering on a promise: polio eradication strategy 2022-26, 2021.

6 WHO. Immunization coverage, 2021. Available: https://www.who.int/news-room/fact-sheets/detail/ immunization-coverage [Accessed 19 Jul 2021]. 